\title{
XLII. On the purification of coal gas; on the ammoniacal liquor of coal gas; and on some singular products obtained from the ammoniacal liquor
}

\section{Mr. George Lowe}

To cite this article: Mr. George Lowe (1819) XLII. On the purification of coal gas; on the ammoniacal liquor of coal gas; and on some singular products obtained from the ammoniacal liquor, Philosophical Magazine Series 1, 53:252, 262-266, DOI: 10.1080/14786441908652134

To link to this article: http://dx.doi.org/10.1080/14786441908652134

曲 Published online: 23 Jul 2009.

Submit your article to this journal $\sqsubset$

山ll Article views: 2

Q View related articles $\widetilde{ }$ 
the cold body placed at the wide end, will be six times as great as in the reverse position. This, it is true, much exceeds what is wanted for our purpose ; but we must make some allowance for rays which are lost by reflection, or which do not emanate perpendicularly from the surface of the ball; and besides, it is a current though doubtful notion, that in the reflection of heat, the angle of incidence is less than that of reflection. At all events, it is hoped that by means of the foregoing explanation the paradox may be solved without the sorry airl of frigorific rays, which certainly deserve no. encouragement in our northern climate. How soon they might be followed by a kindred system of tenelrific rays, it is not easy to say. I am, \&c.

Henty Meikle.

[For a P.S. sent hy the author, but which came to hand too late for unsertion in this place, sec Miscellareous Intelligence at the end of the present Number.]

XLII. On the Purification of Coal Gas ; on the ammoniacal Liquor of Coal Gas; and on some singular Products obtained from the ammoniacal Liquor. By Mr. GEonge LowE, of Derby.

\section{To Mr. Tilloch.}

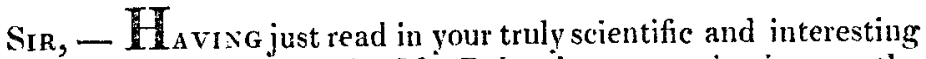
Magazine for last month, Mr. Bolton's communication on the popular subject of coal-gas, in which he honours me with the meed of praise in comnexion with $\mathrm{Mr}$. Parker for our humble endeavours at perfecting this national source of light-thus far I can have no objection that Mr. Bolton should unite us; and for myself, $I$ beg to return him many thanks for a communication which evinces laborious research, judgement, and liberality. But when at one fell swoop he condemns the practice of passing gas through heated surfaces as "faulty and injurious," the credit due to my former communication, and to your pages of last December which record it, demands that I should set Mr. B. right respecting the strange error he has fallen'into, when he thus identifies my plan with Mr. Parker's. If he will have the goodness to refer to it, he will find that the chief view with which it was written, was to show in what we agreed and in what we differed; and that the modus operandi of mine was the very reverse of his! inasmuch as Mr. Parker applies the medium of heat to his gas after it has passed the condenser; but in mine befure!

This difference, which Mr. B. has unfortunately overlooked, he will find, constitutes the sole cause why the former method deteriorates the illuminating power of the gas, whilst the latter materially increases it. After this process of hyper-carbonzing 
the gas, if I may so term it, I do now, as I then stated, "pass it through lime-"-ater." Having explained thus nuch, I can with pleasure proceed hand-in-hand with $\mathrm{Mr}$. Bolton in the flowery path of experiment. We all have, or are likely to have, our holbies. Chemistry has been the one which from early youth thas filled up and rendered both pleasant and protitable the hours of relaxation from more weighty concerns. Like Mr. Bolton, I have visited many gas concerns, both great and small, and can bear witness with him to their often total want of skill, and to the consequent impurity of their gas; to say nothing of the immense expense of outfit, and wear and tear. In some establishments I have seen retorts worn out in three davs; some in three months; and others, though in constant work, (as at a friend's in Birmingham,) not in three years! This speaks volumes as to the necessity of a good plan, and to the effects of the want of it.

It puts me in mind, Mr. Editor, of the pledge which I gave in my former letter, of troubling you with a sketch of the plan of the apparatıs we were then setting up, to light our brewery, offices and house. It is now complete, and that in everv sense. The gas is brought to a red heat, in connexion with oxidizeable surfaces, or not, at pleasure, before leaving the retort, and its quality is as above described: it then passes through a condenser; and lastly, through lime-mud into the gasometer.

I am fully convinced with $\mathrm{Mr}$. B. that there is nothing so cheap, so simple, and so effectual, as lime for purifying. The lights of two Argands by which I am writing, have been burning at least five hours, and the room is as free from any unpleasant smell as if two wax-lights had been burning!-Anong other chemical tests, the nose is not a bad one.-But it is a great point that the lime-washer should be furnished with an agitator to stir up the thickest and most serviceable part of the lime, which otherwise will form a stiff inert mass at the bottom. 'This appendage seems to be wanting in the sketch of Mr. Clegg's washer. The washer we have adopted, you will, I trust, consider as combining in some degree the main requisites of exposure of surface with moderate pressure, united to simplicity and cheapness of structure, as well as being portable; which, on the small scale of a private gas apparatus situated near a dwelling, will be found a great desideratum; as thereby the nuisance which invariably takes place at recharging with fresh lime, is removed to a distance. The accompanying sketch A A (Plate III. fig. l.) represents the section of an eighteen-gallon cask, which may be had for a fow shillings, as it does not require that it shall be a sweet one, though a sound one in point of leakage.

This cask contains the lime mud; $b$ is the handle of the agirator, which is made to take off and on, and is fastened with a pin R 4 

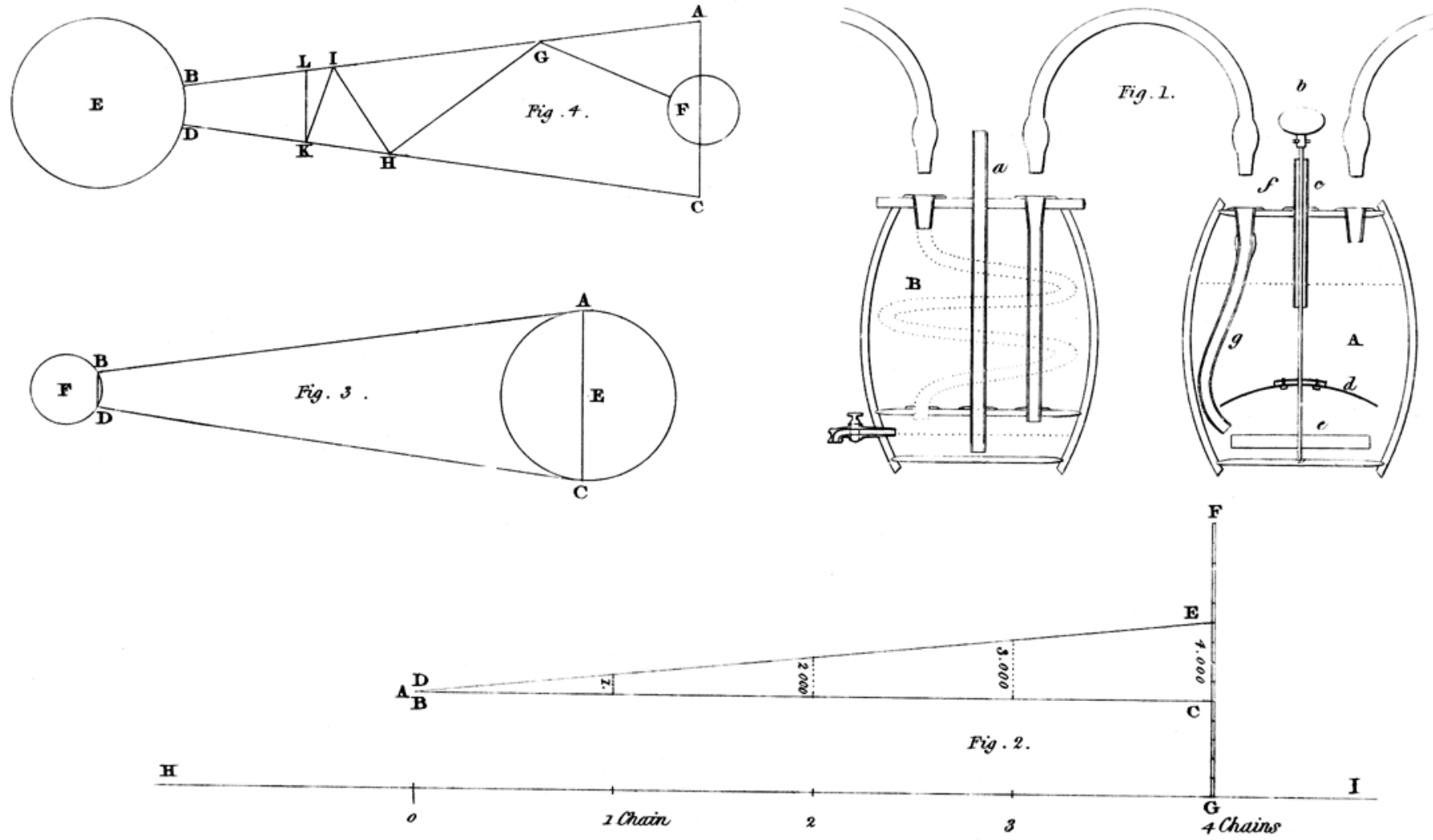
or cotter to the iron rod of the agitator, which passes through the copper tule $c$, which acts both as a water joint to prevent the escape of gas, and as a safety-tube (supposing any stoppage to take place between the washer and gasometer); $d$ is an inverted copper dish, made fast to the iron rod and pierced (except in the centre for the diameter of about six inches) with holes an eighth of an inch in diameter, and at intervals of about an inch. 'This divides the gas into streams of small bubbles, thereby exposing a greater surface to the caustic lime, as well as keeping a quantity of gas under the dish, or shelf, equal to its diameter. $\boldsymbol{e}$ is a strap of iron likewise made fast to the perpendicular rod, which acts as an agitator when the handle $b$ is turned round or forced up and down; $f$ is a brass plug and socket of an inch and quarter internal diameter, to which is soldered the inch and quarter copper pipe $g$, which conveys the gas under the shelf $d$. The brass plugs which convey the gas in and out of the washer, as well as the pipe $c$, are fastened into the cask-head with resin cement.

The condenser will, I trust, explain itself; it is also a cask having a head and bottom, and also an interposed disc a little above the latter, forming a tar chamber, to the bottom of which the tube of safety $a$ descends within half an inch. The top of this cask or refrigerator is open to introduce water, except a staff across the middle, just to steady the brass sockets and safety-tube. The communication pipes are of light inch-lead pipe, to which the plugs are soldered. I have nęver found them leak when well pushed down, and they are well adapted to facilitate the putting any part of the apparatus in or out of comexion in a moment.

You will perhaps be inclined to smile, and say " This smells of the brewery." I am happy however to say, The brewery never smells of it; which is more than some gas concerns can boast.

The peculiar construction of our retort, and the improved plan of setting it up, will shortly come before the public, through the medium of the Society for the Encouragement of Arts, Manufactures and Commerce, should they think it worth their notice.

I have read in a late number of the Journal of Science and the Arts, a short notice that Professor Stromeyer has obtained from coal a new acid, a new gum, and a gum resil, which have the properties of dyeing various colours. But as the method by which he obtainis them is not even hinted at, perhaps the following experiments which I have been making, may not be unacceptable to some of your readers.

\section{On the ammoniacal Liquor of Coal Gas.}

Having long been surprised that this product of the gas manufactory should find such difficulty of being disposed of to advantage, I began a set of experiments to ascertain its constitu- 
ents, and the quantity of ammonia it contained. Having evaporated some of the clear ammoniacal liquor from the tar-tub to dryness, I was surprised to find so little crystallizable salt, and that enveloped in a black mass of carhonaceous and oily matter, highly impregnated with sulphuretted hydrogen. This not being at all satisfactory, I next proceeded to rid it of its sulphuretted hydrogen by oxidizing the sulphur. To this end I poured gently into some ammoniacal liquor some muriatic acid, which caused a blackish precipitate, and kept stirring the liquor as I added the acid: at length a strong effervescence took place, and sulphuretted hydrogen was liberated. I kept adding acid till it caused to effervesce. This I presumed would at the same time neutralize the ammonia and form a muriate of it, or sal ammoniac. Having let it precipitate its black matter, which seems to be a compound of sulphur and carbon, I resumed the evaporating of some of it ; when, to my surprise, after it had been over the lamp some time, it let fall another precipitate, which I collected and washed, and found it possessing a waxy nature, insoluble in water, but readily so in alcohol; imparting to it a reddish brown tint. When rubbed on the finger moistened with alcohol, it gave a permanent brown dye. The evaporation of the remaining portion of liquor was going on, when I was still more surprised to observe amongst the crystals forming at the edge of the evaporating basin, minute globules of a beautiful red, or rather lake colour, floating smartly about, till at leugth by the heat at the edges they boiled, and seemed to undergo a partial decomposition, giving out a very peculiar aromatic smell, but still preserving their bright colour.

After it was evaporated to dryness, I left it for a day or two, at intervals making experiments upon the remaining portion of liquor I had not submitted to heat. If into a test glass full of this a piece of linen be dipped, it will soon become red; but instantly, if a solution of sub-carbonate of potash be dropped upon it, or if a few drops be added to the liquid in the test-glass, it turns of a reddish-brown hue, which partly deposits its colouring matter by standing. By this time the lake-coloured crystals were all deliquesced, and the beautiful colouring matter was floating on the top like oil. This I also collecter. It will not unite with water, but readily so in alcolool. Besides the difference of colour, it possesses jroperties different from the brown deposit which at first took place : it permanently stains the fingers; has a peculiar astringent taste, not unlike tamnin; but is not in the least altered by sulphate of iron. If a portion be pressed upon filtering papei, a colourless oil will spread all round it; or if a small bit be placed upon the tongue, after a miyute or two an intense sensation of burning will be felt, just like that produced by any 
of the essential oils; and if chewed, it sticks to the teeth like resin. Whether this is the new resin, ard the other the gum resin, which M. Stromever has mentioned, it is impossible for me to say, or whether his experiments were made with the coal-tar which contains them. Whether essential oil may be obtained in sufficient quantity to render it worth extracting, I am not prepared to say. But that the ammoniacal liquor will yield sal ammoniac so as to pay for the labour and expense, I have no doubt:-but more of this on some future occasion. Suffice it for the present to say, that if any of the foregoing hints shall in the least help, or stir up others who may have more ability and opportunity for deeper research than myself, I shall rest satisfied that I have neither wasted my own time, nor your pages.

Derby, March 15, 1819.

With great respect I remain yours, \&c.

P.S. Having read the discovery of a new combination of oxygen, hydrogen and carbon, called lampic acid, have any of your correspondents observed the peculiar ethereal smell arising from the slow combustion of coal gas when issuing from an Argand, the cock of which is turned on so little as only to give a blue flame about a quarter of an inch high; will the cause of one account for the other?

* * We beg to add, for the information of our correspondent, that the principal consumption of the ammoniacal hiquor at present is by the sal ammoniac makers. Mr. Lowe put on the margin of the communication he sent to us, several pencil dashes of the two colours described in the foregoing paper: they appear to be pretty solid, and may possibly possess other properties which may ald to their value. The suggestion in his P.S. is ingenious, and we doubt not will soon be put to the test of experience.

XLIII. Formula for calculating the Force of Steam. By Mr. W. Creightos.

\section{To Mr. Tilloch.}

Sin, - IN your Number for February, Dr. Ure having given sone formulas for calculating the elasticity of aqueous vapour, I am induced to communicate one formed some years ago to suit Mr. Dalton's experiments, especially as it is simple, and the results frequently nearer Dr. Ure's numbers than his own calculations.

Let the degrees of Fahrenheit $+\mathrm{S} \mathbf{5}=\mathrm{D}$, and the correspondiug force of steam in inches of mercury $-0 \cdot 09=1$. Then

Log. D $-2 \cdot 22679 \times 6=$ Log. $I$. 